\title{
COMPÓSITO DE NANOCELULOSE BACTERIANA E NANOTUBOS DE CARBONO
}

\author{
G. COLLA ${ }^{1}$, V. H. SOUZA ${ }^{1}$, F. V. BERTI ${ }^{1}$ e L. M. PORTO ${ }^{1}$ \\ ${ }^{1}$ Universidade Federal de Santa Catarina, Departamento de Engenharia Química e Alimentos \\ E-mail para contato: guilherme_colla@intelab.ufsc.br
}

\begin{abstract}
RESUMO - A nanocelulose bacteriana (BNC) e os nanotubos de carbono (NTCs) possuem propriedades que instigam o uso desses materiais na área biomédica. No entanto, a utilização de dispositivos biomédicos contendo NTCs precisa ser acompanhada de estudos de citotoxicidade e biocompatilidade. Foram produzidas membranas de $\mathrm{BNC}$ e de $\mathrm{BNC}+\mathrm{NTC}$ que indicaram visualmente a incorporação dos NTCs na membrana de BNC. As amostras também foram analisadas quanto à sua microestrutura, citotoxicidade e condutividade elétrica. Quanto à microestrutura do compósito de BNC+NTCs pode-se notar a incorporação e adesão superficial dos NTCs na membrana de BNC. A concentração de NTCs usada no inóculo demonstrou não ser citotóxica em linhagem de fibroblastos L929 e conseguiu-se atingir uma condutividade elétrica de $0,00040 \mathrm{~S} \cdot \mathrm{cm}^{-1} \mathrm{o}$ que aponta que o método utilizado para obtenção do compósito pode ser um método alternativo para obtenção de compósitos eletroativos com base em BNC.
\end{abstract}

\section{INTRODUÇÃO}

A nanocelulose bacteriana (BNC) possui propriedades fisico-quimicas interessantes para o seu uso na área biomédica em diversas aplicações, propriedades como capacidade de reter água, resistência à tração e rigidez, cristalinidade, porosidade, formação de uma rede de nanofibras, afinidade biológica e a possibilidade de ser modelada em diferentes estruturas tridimensionais por meio de seu modo de cultivo (Yan et al., 2008). O uso da BNC em aplicações como biomaterial condutor ou dispositivo elétrico é impedido devido a algumas de suas características quando pura, tais como não possuir condutividade elétrica e magnetismo. À vista disso, melhorias devem ser estudadas para que o biomaterial possa se adequar a esse tipo de aplicações. (Erbas et al., 2016)

Nanotubos de carbono (NTCs) são nanomateriais considerados parcialmente unidimensionais com elevadas propriedades mecânicas e elétricas. Dessa forma, os NTCs são estudados na área biomédica para aplicações como biosensores, scaffolds, dispositivo de liberação de fármacos, entre outros. No entanto, a utilização de dispositivos biomédicos contendo NTCs precisa ser acompanhada de estudos de citotoxicidade e biocompatilidade. (Park et al., 2009; Yan et al., 2008) A viabilidade celular, por exemplo, está relacionada à atividade mitocondrial das células e indica, caso estudada em um biomaterial, a citotoxicidade do mesmo, podendo ser avaliada por diferentes métodos como a técnica fotocolorimétrica utilizando-se o reagente MTT. O MTT é um sal de tetrazólio que reduzido a um derivado formazan de cor roxa, devido à atividade oxidativa, indica a existência de função mitocondrial e, por conseguinte, a viabilidade celular (Montes-Fonseca et al., 2012). 
Considerando o contexto até aqui apresentado, o trabalho tem como objetivo a produção de um compósito de BNC e NTCs assim como a análise de sua estrutura, citotoxicidade dos NTCs e condutividade elétrica do compósito.

\section{MATERIAIS E MÉTODOS}

\subsection{Produção das membranas BNC+NTCs}

As membranas foram preparadas em placas de 24 poços com $1 \mathrm{~cm}$ de diâmetro estéreis e $1 \mathrm{~mL}$ de inóculo da bactéria Gluconacetobacter hansenii em meio manitol $\left(25 \mathrm{~g} \cdot \mathrm{L}^{-1}\right.$ de manitol, $5 \mathrm{~g} \cdot \mathrm{L}^{-1}$ de extrato de levedura e $3 \mathrm{~g} \cdot \mathrm{L}^{-1}$ de peptona bacteriológica). O inóculo é preparado no próprio meio de cultura com um pré-inóculo de $10 \%$ do volume total onde são suspensas as bactérias até que o pré-inóculo possua aproximadamente 0,150 de absorbância no espectrofotômetro no comprimento de onda de $660 \mathrm{~nm}$. A uma parte do inóculo também foi adicionado $0,05 \mathrm{mg} \cdot \mathrm{mL}^{-1}$ de NTCs comercial marca Bayer Materials Science. O crescimento bacteriano aconteceu em condição estática a temperatura ambiente durante 12 dias. Depois de 7 dias de cultivo, as membranas foram purificados em solução $0,1 \mathrm{~mol} \cdot \mathrm{L}^{-1} \mathrm{de}$ $\mathrm{NaOH}$ a $50^{\circ} \mathrm{C}$ e após esse período as membranas foram lavadas com água destilada até que $\mathrm{pH}$ da água de enxágue fosse equivalente ao da água usada na lavagem. Esterilizou-se o material em autoclave $\left(121^{\circ} \mathrm{C}\right.$ e $\left.1,1 \mathrm{~atm}\right)$. As membranas de BNC obtidas, tanto com e sem NTCs, foram analisadas em microscopia eletrônica de varredura (MEV).

\subsection{Teste de citotoxicidade}

O protocolo utilizado neste experimento segue o que foi determinado pelo Órgão Internacional de Padronização (International Standard Organization -ISO 10993), sendo que o ensaio in vitro é o primeiro teste para avaliar a bioatividade de qualquer substância para uso em dispositivos biomédicos.

Células de fibroblasto murino da linhagem L-929, na densidade de 2500 células por poço, foram incubadas em placas de cultura de 96 poços, contendo $100 \mu \mathrm{L}$ por poço de meio Dulbecco's modified Eagle's medium (DMEM) suplementado com 10\% de soro fetal bovino (Gibco, BRL), $2 \mathrm{mM}$ de L-glutamina, 4,5 $\mathrm{g} \cdot \mathrm{L}^{-1}$ de glicose, 1,5 $\mathrm{g} \cdot \mathrm{L}^{-1}$ de bicarbonato de sódio, $10 \mathrm{~mL}$ de penicilina e estreptomicina e colocadas em estufa com atmosfera contendo $5 \%$ de $\mathrm{CO}_{2}$, à temperatura de $37^{\circ} \mathrm{C}$. No grupo controle as células foram tratadas apenas com meio de cultura. Após as 24 horas iniciais de incubação o meio de cultura DMEM foi removido e as células foram tratadas com concentrações crescentes de NTC. Foram utilizadas cinco concentrações de NTC puro $\left(0,01,0,05,0,1,1\right.$ e $\left.10 \mathrm{mg} \cdot \mathrm{mL}^{-1}\right)$, todas dispersas em meio de cultura DMEM. Após 48 horas, as soluções foram removidas dos poços e a cada poço foram adicionados $100 \mu \mathrm{L}$ de uma solução $5 \mathrm{mg} \cdot \mathrm{mL}$ de reagente MTT (brometo de 3-[4,5-dimetiltiasol-2-il]-2,5-difeniltetrazol) em meio de cultura DMEM, a fim de observar a atividade mitocondrial das células viáveis. As células foram novamente incubadas por 2,5 horas à temperatura de $37^{\circ} \mathrm{C}$. Logo após a remoção desses reagentes, foram adicionados $200 \mu \mathrm{L}$ de solução dimetilsulfóxido (DMSO) por poço. A absorbância a $570 \mathrm{~nm}$ foi determinada em um 
leitor de microplacas automático. Os resultados foram expressos em porcentagem, assumindo o controle ( $0 \%$ de NTC) como $100 \%$ de atividade metabólica.

\subsection{Teste de condutividade elétrica}

Para o teste de condutividade elétrica utilizou-se o método padrão quatro pontas onde uma corrente foi aplicada entre dois terminais externos, com uma fonte de tensão DC Keithley, modelo 6220. A diferença de potencial foi medida entre os terminais internos, com um eletrômetro da Keithley, modelo 6517A. O compósito foi posicionado entre os terminais externos para a medida da diferença de potencial, alterando-se a corrente no equipamento. A condutividade elétrica foi calculada a partir da Equação 1, substituindo-se os valores de corrente e diferença de potencial.

$$
\sigma=\frac{I}{V} \times \frac{1}{d} \times \frac{\ln 2}{\pi}
$$

Na Equação 1, $\sigma$ é a condutividade elétrica $\mathrm{em} \mathrm{S} \cdot \mathrm{cm}^{-1}$; I é a corrente elétrica, em A; d é a espessura da amostra em cm; V é a Diferença de Potencial em V; e $\ln 2 / \pi$ é o fator de correção.

\section{RESULTADOS E DISCUSSÃO}

\subsection{Produção das membranas BNC/NTCs}

As membranas geradas pelos inóculos podem ser observadas na Figura 1 (a), assim como as micrografias de MEV realizadas (b).

Figura 1 - (a) Imagem macroscópica da BNC e BNC+NTCs (b) micrografia das membranas

\section{BNC pura}

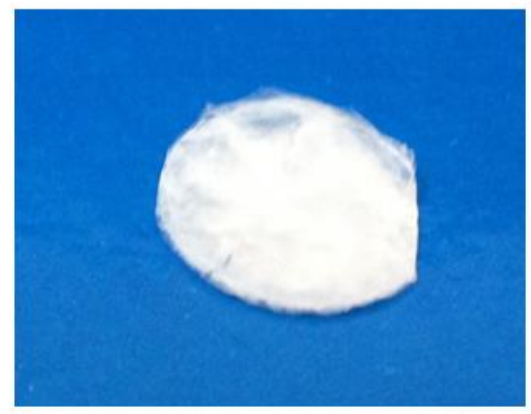

(B)

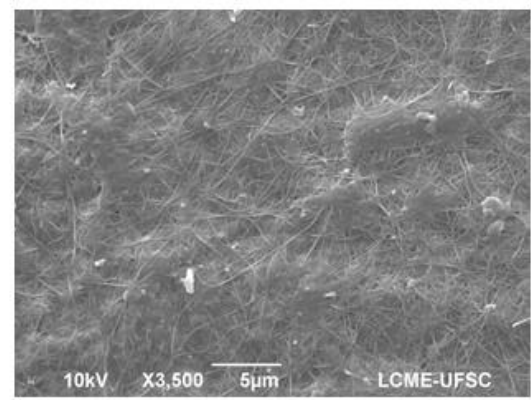

BNC+NTCs
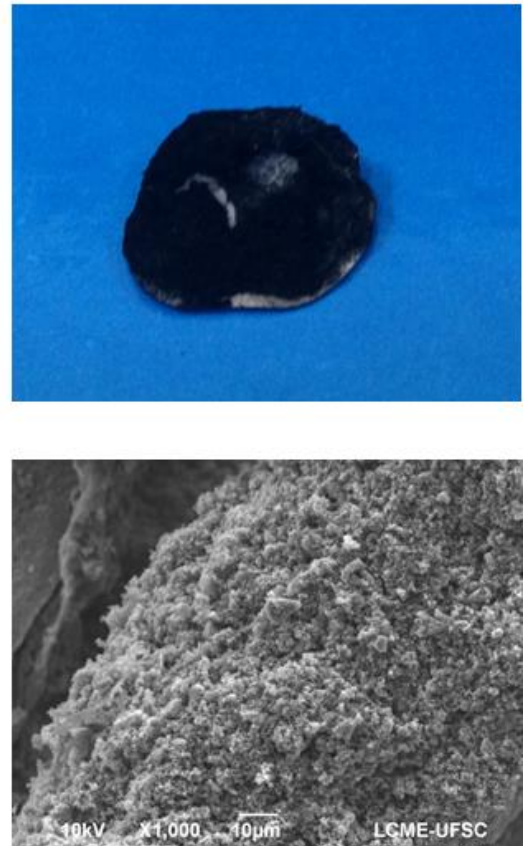
$\mathrm{O}$ aspecto visual das membranas de $\mathrm{BNC}$ pura e BNC+NTCs divergiu bastante. A membrana de BNC pura possui cor esbranquiçada e espessura fina enquanto a membrana de $\mathrm{BNC}+\mathrm{NTC}$ possui cor preta e espessura semelhante à membrana de BNC pura. A cor preta deve-se à incorporação dos NTCs na estrutura tridimensional da membrana, principalmente na superfície porosa que ficou em contato com o meio de cultivo contendo NTCs.

Em relação à microestrutura das membranas observadas nas micrografias pode-se perceber que a de BNC apresentou a estrutura de uma rede de alta densidade de fibras livremente orientadas, como a conhecida pela literatura (Godinho et a.l, 2015). A microestrutura das membranas de $\mathrm{BNC}+\mathrm{NTCs}$ apresentou uma forma fragmentada em toda a superfície, à qual foi atribuída aos NTCs aderidos superficialmente por toda a extensão da membrana.

\subsection{Teste de citotoxicidade}

A Figura 2 mostra os resultados de viabilidade celular das células L929 cultivadas em contato direto com as membranas de BNC e BNC+NTCs para as diversas concentrações de NTCs estudadas.

Figura 2 - Resultado da atividade metabólica dos fibroblastos L929, alterando-se as concentrações de NTCs após 24 h de exposição

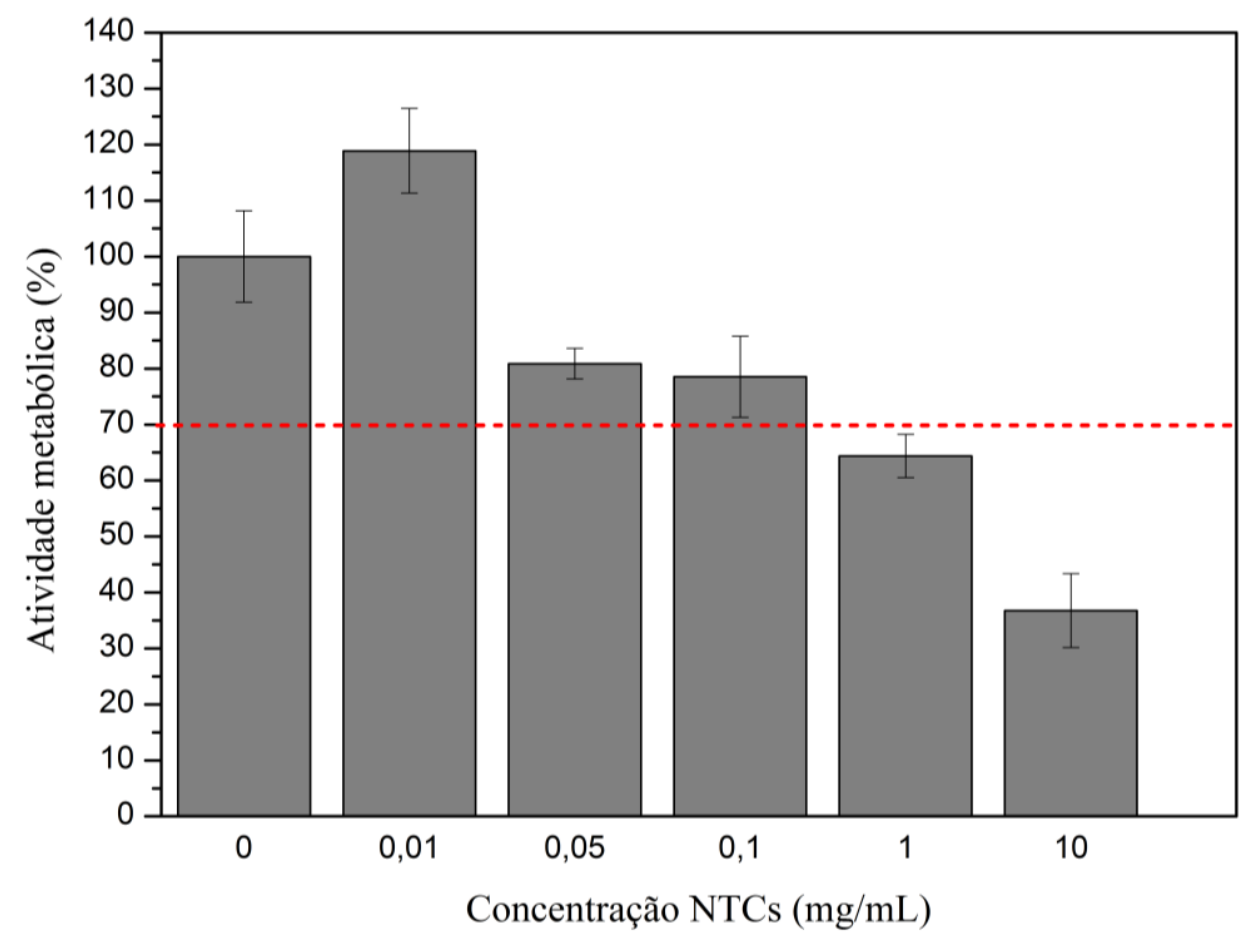

No gráfico a linha vermelha representa o $70 \%$ de viabilidade celular, sendo que todas as concentrações em que a viabilidade celular excedeu os $70 \%$ são consideradas não citotóxicas, e ainda na concentração de $0,01 \mathrm{mg} \cdot \mathrm{mL}^{-1}$ houve um estimulo no crescimentos das células quando comparados com o controle positivo. Considerando-se o método testado, a concentração de $0,05 \%$ utilizada para a produção das membranas é considerada não citotóxica. Os NTCs apresentaram toxicidade a partir da concentração de $0,1 \mathrm{mg} \cdot \mathrm{mL}^{-1}$ após 
24h de exposição. Além disso, sabe-se que a atividade metabólica das células L929 em BNC pura não excede o valor de 70\% (Godinho et a.l, 2015).

\subsection{Teste de condutividade elétrica}

A Tabela apresenta valores de compósitos de nanocelulose bacteriana e suas respectivas condutividades. $\mathrm{O}$ teste realizado resultou em uma condutividade média de $0,00040 \mathrm{~S} \cdot \mathrm{cm}^{-1}$ para o compósito de BNC+NTCs.

Tabela 1 - Comparação entre a condutividade elétrica do presente trabalho e de outros que constam na literatura.

\begin{tabular}{|c|c|c|c|c|}
\hline Compósito & $\begin{array}{l}\text { Método de } \\
\text { produção }\end{array}$ & $\begin{array}{c}\text { Auxiliar de } \\
\text { processo }\end{array}$ & $\begin{array}{c}\text { Condutividade } \\
\text { Elétrica }\left(S \cdot \mathrm{cm}^{-1}\right)\end{array}$ & Referência \\
\hline $\begin{array}{c}\text { BNC com } \\
0,02 \%(\mathrm{~m} / \mathrm{v}) \\
\text { NTCs }\end{array}$ & $\begin{array}{l}\text { Adsorção de } \\
\text { NTCs }\end{array}$ & $\begin{array}{c}\text { Sulfactante } \\
\text { (CTAB) }\end{array}$ & 0,0000037 & $\begin{array}{c}\text { Zhang et al., } \\
2012\end{array}$ \\
\hline $\begin{array}{l}\text { BNC com } 0,05 \\
{\mathrm{mg} \cdot \mathrm{mL}^{-1}}^{\mathrm{de}} \\
\text { NTCs }\end{array}$ & $\begin{array}{l}\text { Dispersão dos } \\
\text { NTCs no } \\
\text { inóculo }\end{array}$ & Nenhum & 0,00040 & $\begin{array}{l}\text { Presente } \\
\text { trabalho }\end{array}$ \\
\hline $\begin{array}{l}\text { BNC com } 9,6 \% \\
(\mathrm{~m} / \mathrm{v}) \text { de NTCs }\end{array}$ & $\begin{array}{l}\text { Imersão da } \\
\text { BNC em uma } \\
\text { dispersão de } \\
\text { NTCs }\end{array}$ & $\begin{array}{l}\text { Sulfactante } \\
\text { (CTAB) }\end{array}$ & 0,14 & $\begin{array}{l}\text { Yoon et } \\
\text { al.,2006 }\end{array}$ \\
\hline $\begin{array}{c}\text { BNC com } 8,32 \% \\
(\mathrm{~m} / \mathrm{v}) \text { de } \mathrm{NTCs}\end{array}$ & $\begin{array}{l}\text { Dispersão dos } \\
\text { NTCs na } \\
\text { superfície da } \\
\text { BNC }\end{array}$ & $\begin{array}{l}\text { Propanossulfonato } \\
\text { e alginato de } \\
\text { sódio }\end{array}$ & 0,189 & $\begin{array}{l}\text { Fugetsu et } \\
\text { al., } 2008 .\end{array}$ \\
\hline
\end{tabular}

Considerando a baixa complexidade do método utilizado, o fato de que não se adiciona nenhum auxiliar de processo, e a concentração utilizada de NTCs, que demonstrou não ser citotóxica, obteve-se uma condutividade elétrica baixa, mas considerável em relação aos outros métodos.

\section{CONCLUSÕES}

O compósito de Nanocelulose Bacteriana e Nanotubos de Carbono foi produzido com sucesso através da produção in situ de membranas de BNC associadas com NTCs. As membranas demonstraram a incorporação dos NTCs, principalmente na superfície, através das análises de MEV pode-se notar a presença dos NTCs aderidos uniformemente à microestrutura do BNC. 
A citotoxicidade dos NTCs foi totalmente dependente da concentração. A utilização de NTCs na proporção de $0,05 \mathrm{mg} \cdot \mathrm{mL}^{-1}$ demonstrou não ser citotóxica para as células L929 após $24 \mathrm{~h}$ de cultivo. O compósito apresentou uma condutividade elétrica de $0,0004 \mathrm{~S} \cdot \mathrm{cm}^{-1}$, o que aponta que o método utilizado para obtenção do compósito pode ser um método alternativo para obtenção de compósitos eletroativos com base em BNC.

\section{REFERÊNCIAS}

ERBAS, E.; KIZILTAS, A.; RHODES, K.; EMANETOGLU, N. W.; BLUMENTRITT, M.; GARDNER, D. J.. Electrically conductive nano graphite-filled bacterial cellulose composites. Carbohydrate Polymers, v. 136, 1144-1151, 2016.

FUGETSU, B.; SANO, E.; SUNADA, M.; SAMBONGI, Y.; SHIBUYA, T.; WANG, X. S. Electrical conductivity and electromagnetic interference shielding efficiency of carbon nanotube/cellulose composite paper. Carbon, v. 46, 1256-1258, 2008.

GODINHO, J. F.; BERTI, F. V.; MÜLlER, D.; RAMBO, C. R.; PORTO, L. M. Incorporation of Aloe vera extracts into nanocellulose during biosynthesis. Cellulose, v. 23(1), 545-555, 2016.

INTERNATIONAL ORGANIZATION FOR STANDARDIZATION, "Biological Evaluation of Medical Devices. Part 5: Tests for In Vitro Cytotoxicity,” ISO 10993-5., vol. 5, pp. 1 $-52,2009$.

MONTES-FONSECA, S. L.; ORRANTIA-BORUNDA, E.; AGUILAR-ELGUEZABAL, A.; HORTA, C. G.; TALAMÁS-ROHANA, P.; SÁNCHEZ-RAMÍREZ, B. Cytotoxicity of functionalized carbon nanotubes in J774A macrophages. Nanomedicine: Nanotechnology, Biology, and Medicine, v. 8(6), 853-859, 2012.

PARK, W.; KIM, H.; KWON, S.; HONG, Y.; JIN, H.. Synthesis of bacterial celluloses in multiwalled carbon nanotube-dispersed medium. Carbohydrate Polymers, v. 77(3), p. 457-463, 2009.

YAN, Z.; CHEN, S.; WANG, H.; WANG, B.; JIANG, J. (2008). Biosynthesis of bacterial cellulose / multi-walled carbon nanotubes in agitated culture. Carbohydrate Polymers, v. 74, p. 659-665, 2008.

YOON, S. H.; JIN, H. J.; KOOK, M. C.; \& PYUN, Y. R. Electrically conductive bacterial cellulose by incorporation of carbon nanotubes. Biomacromolecules, v. 7, 1280-1284, 2006.

ZHANG, X.; LIU, X.; ZHENG, W.; ZHU, J. Regenerated cellulose/graphene nanocomposite films prepared in DMAC/LiCl solution. Carbohydrate Polymers, v. 88, 26-30, 2012. 